\title{
The Impact of Motivation on Work Efficiency for Both Employers and Employees also During COVID-19 Pandemic: Case Study from Armenia
}

\author{
http://doi.org/10.21272/bel.4(3).25-35.2020
}

Gayane Tovmasyan, ORCID: https://orcid.org/0000-0002-4131-6322

$\mathrm{PhD}$ in Economics, Senior Researcher at "AMBERD" Research Center of the Armenian State University of Economics, Lecturer at the Public Administration Academy of the Republic of Armenia

Diana Minasyan, ORCID: https://orcid.org/0000-0001-5493-7454

$\mathrm{PhD}$ in Economics, Lecturer at the Department of Accounting and Auditing of the Armenian State University of Economics, Chief accountant at CJSC "Factory of reinforced bridge concrete structures", The Republic of Armenia

\begin{abstract}
The article summarizes the main arguments and counterarguments within the scientific discussion on motivation and its impact on work efficiency. The main goal of the research is to analyze the impact of motivation on work efficiency for both employees and employers during the COVID-19 pandemic. A systematization of the literary sources on motivation indicates that there are different factors of motivation. Some people are motivated by intrinsic factors, while others by extrinsic. Also, the discussion of some recent studies revealed the influence of pandemic on the motivation of people to work remotely. The majority wants to work from the office as face-to-face contacts and collaboration derives innovation. Analysis in the paper for Armenia is carried out in the following logical sequence: a survey is done, which reveals how employees and employers evaluate the impact of motivation on their work efficiency, which factors of motivation they value, also their suggestions for improving the motivation policy in their workplaces. Methodological tools of the research methods were analysis and synthesis, survey, Pearson Chi square testing. The study reveals that people mainly appreciate both intrinsic and extrinsic motivation factors. From the material incentives which are more important for respondents, the most popular are salaries, rewards and health insurance, and from nonmaterials - career advancement, healthy moral and psychological atmosphere of the organization, flexible work schedule, fair and equal conditions, training courses. According to employees, the organization's motivation policy affects their work efficiency and plays an essential role in the organization's success. This fact is also proved by the statistical testing, that the relationship between these two factors is significant. The main reasons why employees leave the job may be the low salary, conflicts in the team, and the impossibility of career advancement. According to employers, employees are most interested in material incentives. The survey also reveals that people are most motivated when they are in the workplace, and for only $12 \%$ of respondents remotely working is motivating. It shows that in Armenia, people prefer to work from the office. The results have both theoretical and practical significance. It may be useful for organizations to improve motivation policy by changing the available problems, especially after the pandemic.
\end{abstract}

Keywords: Motivation, Work Efficiency, Intrinsic and Extrinsic Factors, COVID-19, Remotely Work.

JEL Classification: M1, M12, M54.

\section{(i)}

This work is licensed under a Creative Commons Attribution 4.0 International License

Cite as: Tovmasyan, G., Minasyan, D. (2020). The Impact of Motivation on Work Efficiency for Both Employers and Employees also During COVID-19 Pandemic: Case Study from Armenia. Business Ethics and Leadership, 4(3), 25-35. http://doi.org/10.21272/bel.4(3).25-35.2020.

(C) The Authors, 2020. This article is published with open access at Sumy State University.

\section{Introduction}

Motivation is one of the main functions of management since it directs and sustains behavior. People do something because they have some needs. Motivation theories explain why people want to do things. Understanding motivation is significant for employers because it impacts the efficiency of employee's work. People may be motivated by intrinsic and extrinsic factors. Intrinsic motivation originates from a source inside the person, while extrinsic originates from a source outside the person. Intrinsic goals are enjoyment, purpose, 
pride, interest, knowledge, and self-worth, while extrinsic goals are money, rewards, deadlines, and punishment. The motivation policy is essential in organizations. If employees are satisfied and feel that the organization values their contribution, they will work better. If employees feel that the organization does not evaluate their efforts and they do not feel appreciated, so the efficiency of their work performance will decrease. The article aims to explore the impact of motivation on work efficiency for employees and employers, especially in the current COVID-19 pandemic situation. The survey was done to investigate which factors, such as intrinsic or extrinsic, are more effective and what motivates employees or what will help them get back to work after the pandemic.

\section{Literature Review}

The literature review explores the essence of motivation, its main types, theories, and some recent studies on motivation and the relationship between motivation and different factors. Motivation arouses, directs, and sustains behavior. Understanding motivation is essential to managers and those responsible for bringing about performance from others. Performance arises when people want to and can perform a task. Performance is a function of motivation and ability - if either is missing, performance will not occur. Motivation theories explain why people want to do things. There are two types of theories: content theories and process theories. Content theories focus on the things that energize and direct behavior and that are internal to individuals. They focus on how needs derive behavior. Maslow's Need Hierarchy, Alderfer's ERG theory, Herzberg's Twofactor theory, McClelland's Learned Needs theory describe that human behavior is driven by the desire to satisfy personal needs - such as survival, safety, social, esteem, growth, achievement, and power needs. Process theories, such as goal-setting theory, reinforcement theory, equity theory, expectancy theory, focus more on cognitive processes and conscious choices of workers (Patterson, 2010: 58). Here are some motivation theories that show the motivating principle (Lee et al., 2016).

Table 1. Some theories of motivation

\begin{tabular}{|l|l|}
\hline \multicolumn{1}{|c|}{ Theory } & \multicolumn{1}{c|}{ Motivating principle } \\
\hline Motives and needs (by Maslow) & Hierarchy of needs: psychological, safety, social, ego, self-actualizing. \\
\hline Expectancy (by Vroom) & Work effort leads to performance and rewards. \\
\hline Equity and justice (by Adams) & Employees strive for equity between themselves and other employees. \\
\hline Goal setting (by Locke and Latham) & $\begin{array}{l}\text { Specific and difficult goals consistently lead to better performance than easy goals or } \\
\text { no goals. }\end{array}$ \\
\hline Cognitive evaluation (by Deci) & External elements affect intrinsic needs, intrinsic rewards and satisfaction. \\
\hline Work design (by Hackman and Oldham) & $\begin{array}{l}\text { The five important job characteristics: skill variety, task identity, task significance, } \\
\text { feedback, autonomy that result in positive employee and organizational outcomes. }\end{array}$ \\
\hline Reinforcement (by Skinner) & $\begin{array}{l}\text { Managers should positively reinforce employee behaviors that lead to positive } \\
\text { outcomes (e.g., with extrinsic rewards). }\end{array}$ \\
\hline
\end{tabular}

Source: Lee et al., 2016

It is necessary to explore intrinsic and extrinsic motivation to understand what motivates people. Intrinsic motivation comes from a source inside the individual, while extrinsic motivation comes from a source outside the individual (Quinn, 2010: 54). Intrinsic motivation is animated by personal enjoyment, interest, or pleasure, whereas extrinsic motivation is governed by reinforcement contingencies (Lai, 2011). According to Turner (2017), an organization's performance culture is impacted by the motivation of an organization's employee. Determining whether an employee's motivation is intrinsic or extrinsic helps organizations see what more of a drive in their performance is. Extrinsic motivation is commonly used to entice employees. Organizations can control the use of extrinsic motivation by deciding the best method of instilling them. Boumas et al. (2012) explored the impact of age on the relationship between work attributes and employees' work motivation and job satisfaction. The results showed that to remain inspired and motivated, older employees appear to be more in need of intrinsic challenging and fulfilling jobs. Also, the positive relationship between career opportunities and motivation was much stronger for younger workers than for older ones. It shows that, particularly, the motivation of younger employees' increases as they are offered more career opportunities. Another study was carried out to examine generational differences in valuing the sources of motivation in workplace behavior between millennials and older generations. The results showed that both extrinsic regulation-material and identified regulation are valued more by millennials compared to older generations, while extrinsic regulation-social and introjected regulation are valued less by millennials compared to older generations (Mahmoud et al., 2020).

Another research was done to investigate the work motivations of employed women in the Maltese labor market. The study identifies 16 aspects that motivate the employed women in Malta to work. These are: for financial independence; to pay for necessities (or day-to-day needs); to meet people and to make new friends (socialization); to keep busy; for skill/ability utilization; to gain a sense of achievement; responsibility; 
recognition; to increase self-esteem; for career advancement; for supervision; to climb up the social ladder; to contribute to the economy of the country; to be creative; variety from housework; to enjoy a more comfortable lifestyle; and to escape from personal problems or bad habits (protection) (Bezzina et al., 2013).

According to Andersen (2018), power-motivated administrators take and actualize decisions and advice, as well as support their subordinates, and control the actions of others. They convince and impact their subordinates with the benefits of organization in mind. Power-motivated managers use their capacity in socially positive means that helps others and the organization. A study by Chen (2012) revealed that nonprofit managers are more likely to show positive work approaches (e.g., job fulfillment, work inclusion, organizational commitment, etc.) than public managers. The attitudinal distinction has two reasons. First is that a more elevated level of rule limitations in the public sector frustrates managers' job attitudes. Second, people engaged in working in the public sector have more substantial extrinsic motivation and more fragile intrinsic motivation. Another interesting research was done to determine the influence of job motivation on the relationship between EI factors (Self Emotional Appraisal, Others' Emotion Appraisal, Regulation of Emotion, and Use of Emotion) and group role efficiency. The analyses showed that the relationships between job motivation and Self Emotional Appraisal (SEA) and between job motivation and Others' Emotional Appraisal (OEA) have a significant impact on service providers' group role efficiency (Othman et al., 2009).

\section{Methodology and Research Methods}

The primary purpose of this research paper is to analyze the impact of motivation on work efficiency for both employees and employers, also during the COVID-19 pandemic. For this purpose, we have analyzed some issues available in the literature. Also, a sociological survey was carried out among employees and employers of different spheres in Armenia, to find out how they evaluate motivation policy of their organization, which types of motivation are essential for them, etc. The main methods used in the paper were: analysis and synthesis and quantitative and qualitative methods, such as statistical method and survey. Statistical methods analyzed the survey results. A database was created, and the key findings were obtained by using Cross-tabulations with Pearson Chi-square coefficient testing (setting significance level $\alpha=0.05$ ). Considering the COVID-19 pandemic situation, because of which the working regimes are changed, and many people must work remotely, we have also analyzed this situation and its impact on work motivation in Armenia and abroad.

\section{Analysis}

The influence of COVID-19 on work motivation. Hamilton Place Strategies, in partnership with Replica, had published the results of their research on June 16, 2020, and we would like to focus on some aspects of it. According to their report, COVID-19 has forced us to think about how we work and what is the most valuable factor in the workplace. Since the need for social distancing, businesses in every sector - manufacturing, retail, food and entertainment, and professional services - have had to reconsider their physical workplaces. All these factors have focused us on thinking about how we work, what we value in our workplace, and what motivates us. According to the report, the office will continue to be important for many companies and workers. The benefits of an office environment - such as training, mentorship, and collaboration - remain as essential as ever. We have already begun to see limitations of remote work for some, with reports of more hours worked, burnout, and potential long-run losses in productivity.

Drawing lines between "life" and "work" was challenging before "work from home." With a viable vaccine still likely months away, there is a question: How can we realize the upsides of an office environment while keeping employees safe and healthy? One of the most important lessons learned is that both companies and workers desire flexibility. The office space will need to adapt (Reimagining Work in the Era of COVID-19, by Hamilton Place Strategies, in partnership with Replica, 2020). CEOs and business leaders, from Google's Sundar Pichai to Accenture's Julie Sweet, have spoken about the importance of the office: in-person interaction matters for innovation, relationships, culture, and more. McKinsey report of April, 2020 found that co-located teams have an easier time building trust and making decisions quickly. It is likely because people prefer to communicate complex information face-to-face (Reimagining work in the era of COVID-19, 2020).

Individuals and companies alike recognize remote work is complementary to, rather than a replacement for, in-person collaboration. Gensler's U.S. Work from Home Survey 2020 found that only 12\% of U.S. workers want to work from home full-time, and most want to spend the majority of the workweek at the office while having the ability to work from home when they wish (U.S. Work From Home Survey, 2020). The study found that $70 \%$ of people want to work in the office for most of their week. However, they want to see changes from the pre-pandemic density levels, ensuring there is more space for physical distancing while addressing noise and cleaning protocols (Cohen A., Hoskins D., 2020). Employees want to get back into the office. They would 
prefer to work in the office at least part of the time was more than double the number who said they would prefer to stay fully remote. Even Stanford economist and remote work advocate Nicholas Bloom say face-toface meetings and in-person collaboration are vital for keeping staff motivated and generating new ideas.

What's more, we are social creatures; social relationships and interpersonal contact tangibly benefit mental and physical health (Reimagining work in the era of COVID-19, 2020). The majority - 76 percent - of respondents said they felt an office setting was "very important" or "somewhat important" for collaboration and innovation. Roughly one-third of respondents said they felt America's long-term innovation and ingenuity would eventually suffer if many companies continue to work remotely.

The training and mentorship of an office environment may be most famous for those just beginning their careers. Large percentages of millennial and Gen $\mathrm{Z}$ workers report feeling less connected to coworkers or having difficulty communicating due to remote work, according to a survey by Smartsheet. Ensuring that everyone has a seat at the table can be difficult over videoconferencing, and "Zoom fatigue" is real (Reimagining Work in the Era of COVID-19, by Hamilton Place Strategies, in partnership with Replica, 2020). Despite being more tech fluent, $95 \%$ of Generation $\mathrm{Z}$ and $93 \%$ of Millennial workers report difficulty working from home due to COVID-19 (Smartsheet, over 90\% of Young Workers Having Difficulty Working from Home, Survey Finds, 2020).

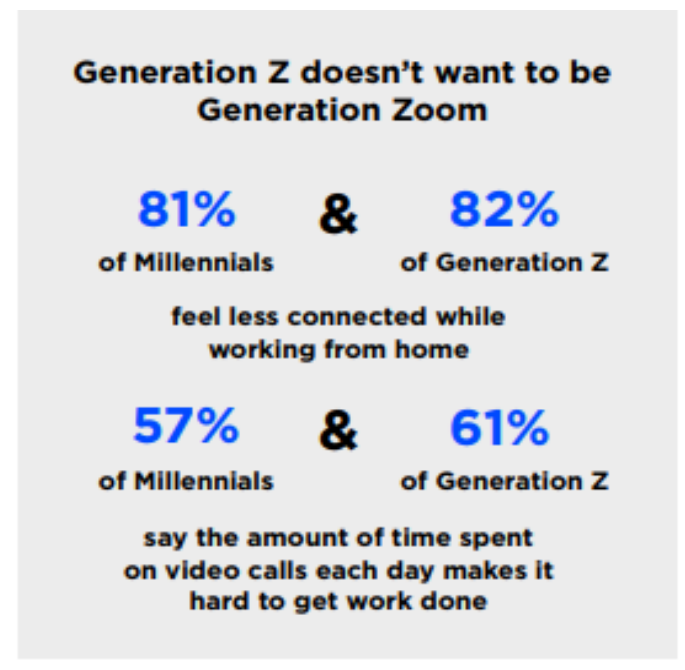

Figure 1. Smart sheet survey results

Source: Reimagining Work in the Era of COVID-19 (2020), Hamilton Place Strategies, in partnership with Replica, taken from Smart sheet / Engine Insights

Besides, Upwork (UPWK), the biggest freelancing website published the results of its third yearly Future Workforce Report, which investigates recruiting practices of more than 1,000 hiring managers situated in the U.S. This year, generational effects on the workforce explored results, investigating explicitly how youthful generations are forming the future of work. The investigation found that $48 \%$ of younger generation directors (composed of Millennials basically, also with early Gen Z managers included) are director-level or higher, indicating they have a significant impact on workforce arranging. This impact will develop and increase with these younger generations making up $58 \%$ of the workforce by 2028, an increase of $38 \%$ from today (Third Annual "Future Workforce Report" Sheds Light on How Younger Generations are Reshaping the Future of Work, 2020). The discussion of some recent reports on people's attitudes about working remotely shows that people are mainly not motivated. Remote working seems good for having flexible time. However, there is now collaboration, innovation, and people spent more time in the Internet, which does not allow them to work effectively.

\section{Results}

We conducted a sociological survey via the Internet on June 30-July 20, 2020, to explore the impact of motivation on work efficiency (also during a pandemic) for both employees and employers. The number of respondents was 100, only 10 of whom were employers. The results of the survey are as follows: $75 \%$ of participants were female, $25 \%$-male. $52 \%$ of participants were $26-40$ years old, $44 \%$ were up to 25 years old. $35 \%$ of participants had 1-5 years of work experience. The monthly income of $44 \%$ was up to 150000 AMD. 
Table 2. Main characteristics of survey participants

\begin{tabular}{|c|c|}
\hline & Share in the total, \% \\
\hline \multicolumn{2}{|l|}{ Gender } \\
\hline Female & 75 \\
\hline Male & 25 \\
\hline \multicolumn{2}{|l|}{ Age } \\
\hline Up to 25 years old & 44 \\
\hline $26-40$ years old & 52 \\
\hline 41-60 years old & 3 \\
\hline 61 and older & 1 \\
\hline \multicolumn{2}{|l|}{ Occupation } \\
\hline Financial sector & 19 \\
\hline Education sphere & 21 \\
\hline Production & 5 \\
\hline Trade & 3 \\
\hline Construction & 10 \\
\hline Tourism & 4 \\
\hline Health & 2 \\
\hline Public sphere & 1 \\
\hline IT & 18 \\
\hline Other & 17 \\
\hline \multicolumn{2}{|c|}{ The duration of your work experience } \\
\hline Up to 1 year & 21 \\
\hline $1-5$ years & 35 \\
\hline $5-10$ years & 20 \\
\hline $10-15$ years & 17 \\
\hline 15 years and more & 7 \\
\hline \multicolumn{2}{|c|}{ Monthly income } \\
\hline Up to $150000 \mathrm{AMD}$ & 44 \\
\hline $150001-300000 \mathrm{AMD}$ & 31 \\
\hline 300001-450000 AMD & 18 \\
\hline 450001-600000 AMD & 3 \\
\hline $600001 \mathrm{AMD}$ and more & 4 \\
\hline
\end{tabular}

Source: Own adjustment based on the survey results

It is interesting to notice that survey participants mainly appreciate both intrinsic and extrinsic motivation factors. The survey results show that from the material incentives, which are more important for respondents, the most popular are salaries, rewards, and health insurance. From non-material, there are career advancement, healthy moral and psychological atmosphere of the organization, flexible work schedule, fair and equal conditions, training courses. $89 \%$ of respondents mentioned that they work with pleasure.

Table 3. The most important motivation types for survey participants

\begin{tabular}{|l|c|}
\hline \multicolumn{1}{|c|}{ For you is more important } & Share in the total, \% \\
\hline $\begin{array}{l}\text { Intrinsic motivation factors (interest, growth, learning, knowledge, purpose, pleasure, self- } \\
\text { expression) }\end{array}$ & 26 \\
\hline Extrinsic motivation factors (reward, punishment, competition, deadlines, salary increase, prize) & 3 \\
\hline Both of them Which material incentives are most important to you? & 71 \\
\hline It is difficult to answer & - \\
\hline \multicolumn{1}{|c|}{ What are the most important non-material incentives for you? } & 80 \\
\hline Salary & $\begin{array}{c}\text { (participants could mention } \\
\text { more than one option), \% }\end{array}$ \\
\hline Reward & 24 \\
\hline Additional fee & 34 \\
\hline Health insurance & 23 \\
\hline Free transport & 31 \\
\hline Additional paid vacations & 1 \\
\hline Using the materials of the organization & (participants could mention \\
\hline \multicolumn{1}{|c|}{ more than one option), \% }
\end{tabular}


Table 3 (cont.). The most important motivation types for survey participants

\begin{tabular}{|l|c|}
\hline Fair and equal conditions & 49 \\
\hline Security at workplace & 26 \\
\hline Flexible work schedule & 50 \\
\hline International business trips & 1 \\
\hline \multicolumn{1}{|c|}{ Which motivational stimuli are most important to you? } & Share in the total, $\%$ \\
\hline Material You work & 7 \\
\hline Non material & 11 \\
\hline Both of them & 81 \\
\hline It is difficult to answer & Share in the total, $\%$ \\
\hline & 89 \\
\hline With pleasure & 8 \\
\hline Imposed & 3 \\
\hline Other & \\
\hline
\end{tabular}

Source: Own adjustment based on the survey results

It was also interesting to reveal how people work these days during the COVID 19 pandemic and how it motivates them. The results show that $45 \%$ of participants work remotely, $31 \%$ - in the workplace. However, $52 \%$ mentioned that they are more motivated when they are in the workplace, and only $12 \%$ of respondents working remotely is motivating. It shows that in Armenia, many people prefer to work from the office, like in the research motioned above by American consultant, Gensler, who found that for only $12 \%$ of workers in the United States want to work every day from home. In comparison, $70 \%$ of people miss their workplaces for reasons like meeting with colleagues, socializing, solving faces, face work issues, be part of a community and have access to technology (Reimagining Work in the Era of COVID-19 (2020), Hamilton Place Strategies, in partnership with Replica).

Table 4. Working mode and its motivation for survey participants

\begin{tabular}{|l|c|}
\hline \multicolumn{1}{|c|}{ Do you work remotely or in the workplace now? } & Share in the total, \% \\
\hline Remotely (online) & 45 \\
\hline In the workplace & 31 \\
\hline Both, online and in the workplace & 13 \\
\hline I do not work at this moment & 11 \\
\hline \multicolumn{1}{|c|}{ Which mode of work motivates you the most? } & Share in the total, \% \\
\hline Remotely (online) & 52 \\
\hline In the workplace & 28 \\
\hline A combination of the two & 8 \\
\hline It is the same for me & \\
\hline
\end{tabular}

Source: Own adjustment based on the survey results

The number of employers who participated in the survey, was only 10. They mentioned the main types of motivation which they use to promote employees.

Table 5. Best type of motivation according to employers

\begin{tabular}{|l|c|}
\hline \multicolumn{1}{|c|}{$\begin{array}{c}\text { Which types of motivation do you use as an employer to promote your } \\
\text { employees? }\end{array}$} & $\begin{array}{c}\text { number of respondents } \\
\text { Total number of respondents was 10) }\end{array}$ \\
\hline Salary & 6 \\
\hline Reward & 3 \\
\hline Additional fee & - \\
\hline Health insurance & - \\
\hline Free transport & - \\
\hline Additional paid vacations & 3 \\
\hline Career promotion & 2 \\
\hline Training courses & 3 \\
\hline Opportunity to make responsible decisions & 3 \\
\hline Security at workplace & 4 \\
\hline Flexible work Schedule & 2 \\
\hline Participation in the administrative decision-making process & 1 \\
\hline All the mentioned and more & \\
\hline In your opinion, employees are more interested in? & \\
\hline Material incentives & \\
\hline Non material incentives & \\
\hline In both & \\
\hline It is difficult to answer & - \\
\hline Sourc: Own adjustre & \\
\hline
\end{tabular}

Source: Own adjustment based on the survey results 
The employers were asked to answer the following question: "How do you think employees should be motivated to work more effectively and dedicated to the organization?" They gave some answers:

The best motivation is material (it is necessary to increase salaries, rewards).

Appreciate each person's contribution, respect everybody, value them so that they can consider themselves important in the success of the organization and based on it they will work with dedication and efficiency.

Everyone's opinion should be considered, training courses should be organized often, and salaries should be reviewed at least once every four months.

Independence and freedom to make decisions.

The number of employees who participated in the survey was 90. Most of them said that the organization's motivation policy affects their work efficiency, and they have an essential role in the organization's success. They mentioned the material and nonmaterial incentives used in their organization: salary, reward, flexible work schedule, etc.

Table 6. Opinion of employees about motivation policy and their work effeciency

\begin{tabular}{|l|c|}
\hline \multicolumn{1}{|c|}{$\begin{array}{c}\text { Does the motivation policy used by the organization affect on your work } \\
\text { effectiveness? }\end{array}$} & $\begin{array}{c}\text { Number of respondents } \\
\text { (Total number of respondents was 90) }\end{array}$ \\
\hline Yes & 67 \\
\hline No & 12 \\
\hline It is difficult to answer & 62 \\
\hline Do you have an important role in the success of your organization? & 6 \\
\hline Yes & 22 \\
\hline No & \\
\hline It is difficult to answer & \\
\hline $\begin{array}{l}\text { What types of material and non material motivation are used in your } \\
\text { organization? }\end{array}$ & 63 \\
\hline Salary & 47 \\
\hline Reward & 29 \\
\hline Additional fees & 31 \\
\hline Health insurance & 17 \\
\hline Free transport & 25 \\
\hline Additional paid vacations & 31 \\
\hline Career promotion & 36 \\
\hline Training courses & 25 \\
\hline Opportunity to make responsible decisions & 32 \\
\hline Security at workplace & \\
\hline $\begin{array}{l}\text { Flexible work } \\
\text { Schedule }\end{array}$ & \\
\hline Other & \\
\hline
\end{tabular}

Sources: Own adjustment based on the survey results

The employees were asked to rate their satisfaction with the motivational policy applied by their organization, evaluating it on a scale of 1-10 (ten very satisfied, one very dissatisfied). The average score is 7.4. The employees were also asked to evaluate their working conditions. The results show that they are mainly not satisfied with the transport transfer of employees, somehow satisfied with remuneration for work, and very satisfied with the relationships with managers.

Table 7. How satisfied are you with your working conditions? (number of participants)

\begin{tabular}{|l|c|c|c|}
\hline & Very satisfied & Somehow satisfied & Not satisfied \\
\hline Working mode & 47 & 28 & 2 \\
\hline Working conditions & 44 & 28 & 3 \\
\hline Break conditions & 46 & 21 & 7 \\
\hline Terms of transport transfer of employees & 18 & 25 & 17 \\
\hline Working relationships in the team & 61 & 19 & 2 \\
\hline Relationships with leaders & 58 & 15 & 5 \\
\hline Remuneration for work & 31 & 34 & 5 \\
\hline Material supply & 28 & 29 & \\
\hline
\end{tabular}

Source: Own adjustment based on the survey results

Employers mentioned that the main reasons to leave the job are low salary, conflicts in the team, the impossibility of career advancement. 
Table 8. Reasons for dismissal according to employees

\begin{tabular}{|l|c|}
\hline \multicolumn{1}{|c|}{ Which may be the main reasons for your dismissal? } & $\begin{array}{c}\text { Number of participants } \\
\text { (Total number of respondents was 90) }\end{array}$ \\
\hline Low salary & 49 \\
\hline Technical problems that arose during the work & 6 \\
\hline Location of the workplace, away from the place of residence & 21 \\
\hline Conflicts in the team and immoral atmosphere & 45 \\
\hline Conflicts with the managers & 38 \\
\hline Health reasons & 23 \\
\hline Family reasons & 20 \\
\hline The impossibility of career advancement & 40 \\
\hline $\begin{array}{l}\text { Other (violation of my rights, the stagnation of the organization, new job with higher salary } \\
\text { and more interesting) }\end{array}$ & 3 \\
\hline
\end{tabular}

Source: Own adjustment based on the survey results

The employees also mentioned the types of support which they need in order to transit to the old working mode after working remotely.

Table 9. The main types of support which is important to transit to the old working mode after working remotely for employees

\begin{tabular}{|l|c|}
\hline $\begin{array}{c}\text { What support is most important for you to make the transition to the old working } \\
\text { mode more smoothly after working remotely? }\end{array}$ & Number of participants \\
\hline Improving the working environment & 38 \\
\hline Communication with partners & 38 \\
\hline Personal work area & 31 \\
\hline Corporate life & 25 \\
\hline Rewards & 21 \\
\hline Safe working place & 29 \\
\hline None of the above mentioned will change anything & 1 \\
\hline
\end{tabular}

Source: Own adjustment based on the survey results

The employees also had the opportunity to make suggestions for improving their organization's motivation policy, and they mentioned the following:

1. It is necessary to improve the moral and psychological atmosphere, to create an effective system of job evaluation and fair conditions for career promotion for all, to exclude the influence of relatives and other connections,

2. Provision of appropriate bonuses according to overload work periods,

3. Equal treatment of employees, respect for employee rights,

4. Evaluate the overtime work of the employee, pay bonuses,

5. The employer must give paid vacations, which does not work in our organization,

6. Create an opportunity for training,

7. Professional growth, job expansion, flexible work schedule, health insurance,

8. Some part of decision making can be reduced to lower levels,

9. Motivation policy should be clearly organized, not dependent on the personal discretion of managers,

11. Application of nonmaterial incentives,

12. Increasing the number of computers in the workplace,

13. Do charity,

14. Meetings should be held often, in addition to listening to and accepting the employee's complaint about the job. To improve the work process as much as possible so that the employee is happy to think that the employer received his word, and it was not just an opinion voiced by the employee.

15. Opportunity for career advancement,

16. To increase salaries.

\section{Discussion}

We have carried out Pearson Chi square analysis to see if there is any significant relationship between some factors. We have derived some hypotheses:

1. Is there any significant relationship between monthly income size and working mode (remotely or in the office)?

H1: There is a significant relationship between monthly income size and working mode. 
HO: There is no significant relationship between monthly income size and working mode.

2. Is there any significant relationship between duration of work experience and working mode (remotely or in the office)?

\section{H1: There is a significant relationship between duration of work experience and working mode.}

HO: There is no significant relationship between duration of work experience and working mode.

3. Is there any significant relationship between the influence of the motivation policy used by the organization on work motivation and having an important role in the success of the organization?

H1: There is a significant relationship between the motivation policy used by the organization on work motivation and having an important role in the success of the organization.

HO: There is no significant relationship between the motivation policy used by the organization on work motivation and having an important role in the success of the organization.

4. Is there any significant relationship between working mode (remotely or in the office) and motivational stimuli?

H1: There is a significant relationship between working mode (remotely or in the office) and motivational stimuli.

H0: There is no significant relationship between working mode (remotely or in the office) and motivational stimuli.

5. Is there any significant relationship between monthly income size and motivation factors?

H1: There is a significant relationship between monthly income size and motivation factors.

H0: There is no significant relationship between monthly income size and motivation factors.

The testing shows that only for the third hypothesis the significance level is under 0.05 , this means that we reject the null hypothesis that there is no significant relationship between the influence of the motivation policy used by the organization on work motivation and having an essential role in the success of the organization. It means that the relationship is very significant. So, when people think that they have a crucial role in the organization's success, the motivation policy used by the organization has an impact on their work motivation. Anyhow, this shows that if people are satisfied with the motivation policy, they will work hard. In all other cases, the significance level is more than 0.05 , so we do not reject the null hypothesis, and this means that there is no significant relationship between the factors.

Table 10. Chi-Square Testing

\begin{tabular}{|l|c|}
\hline \multicolumn{1}{|c|}{ Factors } & App.sig. \\
\hline monthly income size * working mode & 0.127768229 \\
\hline duration of work experience * working mode & $2.83719 \mathrm{E}-05$ \\
\hline $\begin{array}{l}\text { the influence of the motivation policy used by the organization on work motivation * having an } \\
\text { important role in the success of the organization }\end{array}$ & $\mathbf{0 . 0 0 0 5 0 6 7 1 5}$ \\
\hline working mode * motivational stimuli & 0.934182863 \\
\hline monthly income size * motivation factors & 0.438637845 \\
\hline
\end{tabular}

Sources: The data of survey results analyzed via Excel

\section{Conclusion}

Thus, the survey results show that people mainly appreciate both intrinsic and extrinsic motivation factors. According to employees, the motivation policy of the organization affects their work efficiency, and they play an essential role in the organization's success. The main reasons employees leave the job may be the low salary, conflicts in the team, and the impossibility of career advancement. According to employers, employees are most interested in material incentives. The results have both theoretical and practical significance. The analysis proves that the organization's motivation policy is an essential tool for affecting the effectiveness of employees' work. The statistical testing also shows the significant relationship between the influence of the motivation policy used by the organization on work motivation and having an essential role in the success of the organization.

The survey also reveals some problems and suggestions according to employees and employers. Such analyses should be done in every organization to find issues and improve motivation policies. The analysis is also crucial as it reveals some aspects of work connected with the Covid-19 pandemic. We tried to find out the opinion of Armenians about the efficiency of working remotely. We also analyzed the available reports about how the citizens of other countries think about the efficiency of working from home. $52 \%$ of participants mentioned 
that they are more motivated when they are in the workplace, and for only $12 \%$ working remotely is motivating. Flexible workplace, personal space are the factors that will help people to get back to work safely and quickly, as many people need it. Additionally, one of the most important things is the distance between home and the workplace. During the pandemic, public transportation in most countries is not working correctly or does not work at all, so it is quite difficult to get to one's workplace if one does not have a car or any other mode of transportation. Moreover, not all companies can serve free transportation services for their workers. Most of them are not even able to cover their costs, considering the difficulties by COVID19.

We should also take into consideration that there are some advantages for working at home. There is no need for a dress code; there are no expenses spent on transportation; companies do not spend a lot of money on office space rent, utility bills and other costs. This pandemic changes the way of businesses; there is no need to keep one at the workplace till the end of the workday and waste their time, you can motivate them to do the same work in less amount of time and more productively, so they will work not for time, but a result. It means that the Covid-19 pandemic changed attitudes of work and motivation, revealing the advantages and disadvantages of working in offices and remotely. So, after the pandemic, many offices should consider all the factors mentioned above and make the work mode more flexible to motivate people in the best way.

Author Contributions. Conceptualization, Gayane Tovmasyan and Diana Minasyan; data curation, Gayane Tovmasyan and Diana Minasyan; formal analysis, Gayane Tovmasyan and Diana Minasyan; investigation, Gayane Tovmasyan and Diana Minasyan; methodology, Gayane Tovmasyan and Diana Minasyan; project administration, Gayane Tovmasyan and Diana Minasyan; resources, Gayane Tovmasyan and Diana Minasyan; software, Gayane Tovmasyan and Diana Minasyan; supervision, Gayane Tovmasyan and Diana Minasyan; validation, Gayane Tovmasyan and Diana Minasyan; visualization, Gayane Tovmasyan and Diana Minasyan; writing - original draft, Gayane Tovmasyan and Diana Minasyan; writing - review \& editing, Gayane Tovmasyan and Diana Minasyan.

Funding. There is no funding for this research.

\section{References}

1. Andersen, J. A. (2018). Managers' Motivation Profiles: Measurement and Application. SAGE Open, 8(2), 1-9. https://doi.org/10.1177/2158244018771732.

2. Bezzina, F., Azzopardi, R. M., Vella, G. (2013). Understanding and Assessing the Work Motivations of Employed Women: Insights into Increasing Female Participation Rates in the Maltese Labor Market. SAGE Open, 3(3), 1-14. https://doi.org/10.1177/2158244013502987.

3. Boumans, N. P. G., Jong, A. H. J., Janssen, S. M. (2012). Age-Differences in Work Motivation and Job Satisfaction. The Influence of Age on the Relationships between Work Characteristics and Workers' Outcomes. The International Journal of Aging and Human Development, 73(4), 331-350. https://doi.org/10.2190/AG.73.4.d.

4. Chen, C. (2012). Explaining the Difference of Work Attitudes Between Public and Nonprofit Managers: The Views of Rule Constraints and Motivation Styles. The American Review of Public Administration, 42(4), 437-460. https://doi.org/10.1177/0275074011402192.

5. Cohen, A., Hoskins, D. (2020). Insights from Gensler's U.S. Work From Home Survey 2020. Available at: https://www.gensler.com/research-insight/blog/insights-from-genslers-u-s-work-from-home-survey-2020, (Accessed: 05.08.2020).

6. Jones, C. (2020). What 47 Million People Being Laid Off Looks Like. Available at: https://www.forbes.com/sites/chuckjones/2020/03/31/what-47-million-people-being-laid-off-lookslike/\#5b8d0c6458b8, (Accessed: 05.08.2020).

7. Korman, K. and Mujtaba, B.G. (August 2020). Corporate Responses to COVID-19 Layoffs in North America and the Role of Human Resources Departments. Reports Global Health Research, 3(2), 1-17. DOI: $10.29011 / 2690-9480.100122$.

8. Lai, E.R. (2011). Motivation: A Literature Review, Research Report, Pearson, 1-44. Available at: https://images.pearsonassessments.com/images/tmrs/Motivation Review final.pdf, (Accessed: 05.08.2020).

9. Lamp, M. (2020). How to Manage Layoffs Humanely and Remotely During COVID-19. Available at: https://jobbatical.com/resources/how-to-manage-layoffs-humanely-and-remotely-during-covid-19, (Accessed: 05.08.2020). 
10.Lee, M. T., Raschke, R. L. (2016). Understanding employee motivation and organizational performance: Arguments for a set-theoretic approach. Journal of Innovation \& Knowledge, 1(3), 162-169. https://doi.org/10.1016/j.jik.2016.01.004.

11.Mahmoud, A. B., Reisel, W. D., Grigoriou, N., Fuxman L., Mohr, I. (2020). The reincarnation of work motivation: Millennials vs older generations. International Sociology, 35(4), 393-414, https://doi.org/10.1177/0268580920912970.

12.Miller, C. (2020). The Effect of COVID-19 on the U.S. Economy. Available at: https://www.fpri.org/article/2020/03/the-effect-of-covid-19-on-the-u-s-economyl,(Accessed: 05.08.2020).

13.Othman, A. K., Abdullah, H. S., Ahmad, J. (2009). The Influence of Work Motivation on Emotional Intelligence and Team Effectiveness Relationship, Vision. The Journal of Business Perspective, 13(4), 1-14. https://doi.org/10.1177/097226290901300401.

14.Patterson, C. (2010). Management Briefs: Management and Leadership Theory Made Simple, 72p., $1^{\text {st }}$ edition, bookboon.com, ISBN 978-87-7681-547-9.

15.Quinn, S. (2010). Management Basics, 75p., $1^{\text {st }}$ edition, bookboon.com, ISBN 978-87-7681-717-6.

16. Reimagining Work in the Era of COVID-19, (2020). Hamilton Place Strategies, in partnership with Replica, 12p. Available at: https://res.cloudinary.com/wework/image/upload/v1592247630/Reimagining_Work_in_the_Time_of_COVI D-19.pdf, (Accessed: 05.08.2020).

17.Turner, A. (2017). How does intrinsic and extrinsic motivation drive performance culture in organizations? Cogent Education, 4(1). DOI: 10.1080/2331186X.2017.1337543.

18.Third Annual "Future Workforce Report" Sheds Light on How Younger Generations are Reshaping the Future of Work, (2020). Available at: https://www.upwork.com/press/2019/03/05/third-annual-futureworkforce-report/, (Accessed: 05.08.2020).

19.U.S. Work From Home Survey 2020, GENSLER RESEARCH INSTITUTE, https://www.gensler.com/uswfh-survey-2020-wfh-reinforces-the-benefits-of-the-office (Accessed: 05.08.2020).

20.Villa, L. (2020). Millions of Americans Have Been Laid Off Amid the Coronavirus Outbreak. Here's What it's Like to Be One of Them. Available at: https://time.com/5812538/coronavirus-economic-damageworkers/, (Accessed: 05.08.2020). 